\title{
Association Between Sugar-Sweetened Beverage Consumption as Meal Substitutes, Workload, and Obesity in Nurses: A Cross-Sectional Study
}

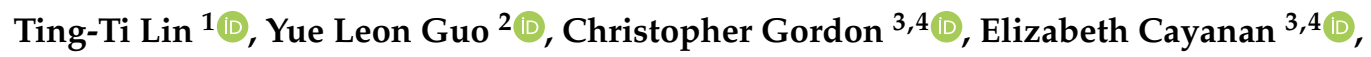 \\ Yi-Chuan Chen ${ }^{5}{ }^{(0)}$, Chung-Mei Ouyang ${ }^{6}$ and Judith Shu-Chu Shiao ${ }^{5, *(1)}$ \\ 1 School of Nursing, National Defense Medical Center, 161, Sec. 6, Minquan E Road., Neihu Dist., \\ Taipei 11490, Taiwan; tlin@mail.ndmctsgh.edu.tw \\ 2 Environmental and Occupational Medicine, National Taiwan University (NTU) College of Medicine and \\ NTU Hospital, 1, Sec. 1, Jen-Ai Road, Taipei 10051, Taiwan; leonguo@ntu.edu.tw \\ 3 Susan Wakil School of Nursing and Midwifery, The Faculty of Medicine and Health, University of Sydney, \\ 88 Mallett St., Camperdown, NSW 2050, Australia; christopher.gordon@sydney.edu.au (C.G.); \\ elizabeth.cayanan@sydney.edu.au (E.C.) \\ 4 CIRUS Centre for Sleep and Chronobiology, Woolcock Institute of Medical Research, Glebe 2037, Australia \\ 5 School of Nursing, College of Medicine, National Taiwan University, 1, Sec. 1, Jen-Ai Rd., \\ Taipei 10051, Taiwan; yichuan1201@gmail.com \\ 6 Department of Nutrition, National Taiwan University Hospital Hsin-Chu Branch, 25., Ln. 422, Sec. 1, \\ Jingguo Rd., HsinChu City 33059, Taiwan; maggieoy@gmail.com \\ * Correspondence: scshiao@ntu.edu.tw; Tel.: +886-223123456; Fax: +886-223933391
}

Received: 31 October 2019; Accepted: 4 December 2019; Published: 7 December 2019

\begin{abstract}
Background: High occupational stress has been associated with altered eating behaviors and obesity. Occupational stress is reported to be high in Asian countries. Furthermore, many Asian countries are increasingly consuming Western-type foods (e.g., incorporating drinks with meals) which collectively may also be contributing to obesity. Therefore, the aim of this study was to examine (a) associations between sugar-sweetened beverage (SSB) consumption as meal replacement and obesity and (b) associations between workload and substituting meals with SSB in nurses. Methods: A representative sample of 854 hospital-based nurses completed a structured questionnaire about SSB consumption, workload, and body mass index (BMI). Log binomial regression models were employed to test associations between SSBs and obesity rates and associations between workload and SSBs. Results: Most participants (57.6\%) consumed SSBs as meal replacements during work. This was related to high workloads during shifts. Substituting SSBs for meals was significantly associated with increased likelihood of obesity (aPRR $=1.4,95 \% \mathrm{CI}(1.1,1.7))$. Workload was positively associated with SSB intake as meal substitutes $(\mathrm{aPRR}=1.4,95 \% \mathrm{CI}(1.2,1.6))$. Conclusions: Our findings show that SSBs are used as meal substitutes and is due to the workload demands. Sugar-sweetened beverage consumption is also positively associated with the increased likelihood of obesity. Interventions that modify workloads and decrease SSB consumption may improve workers' eating behaviors and health.
\end{abstract}

Keywords: eating behaviors; empty calorie beverage; nurse; occupational stress; weight gain

\section{Introduction}

Globally, it has been estimated that one-third of working populations is either overweight or obese $(33 \%-36 \%)$ [1,2]. This has serious population-level consequences, as obesity has been shown to be an independent risk factor for chronic diseases (e.g., type 2 diabetes) [3-7]. While the causes of obesity are complex, numerous studies have shown that increased sugar-sweetened beverage (SSB) consumption 
can be obesogenic [6,8-10]. It has been documented that hospital nurses tend to cope with fatigue by consuming sugar-sweetened food or SSBs at work [11]. In Asian countries, studies have suggested that unhealthy eating behaviors (e.g., food consumption misaligned with dietary recommendations) are prevalent among hospital nurses [12-14]. However, to the best of our knowledge, it is still unclear whether SSB intake at work is related to workers' obesity, and what factors account for workers' high prevalence rate of unhealthy eating behaviors.

Occupational stress modifies obesity prevalence and dietary consumption of low-nutrient food. Studies have shown occupational stress is associated with obesity $[15,16]$, whereas others have not shown any relationship $[17,18]$. Recent evidence showed that low job control was significantly associated with workers' increased risk of long-term weight gain. Among female workers, high work demands contributed to long-term weight gain [1].

The Transactional Model of Stress and Coping suggests that stress is associated with people's health behaviors that are influenced by how they appraise and cope with their stress [19]. Studies have linked occupational stress to increased likelihood of abnormal eating behaviors (e.g., emotional eating) [20-22] and greater intake of low-nutrient food (e.g., sweetened snacks) [23-26]. Time availability for food ingestion has also been linked to people's healthy eating behaviors [27-29] with time pressure contributing more to workers' decisions on food consumption compared to appetite [30]. Workers appear to prefer fast food consumption due to the high work demands and lack of break times [31]. Therefore, high occupational workload may negatively impact workers' time availability for eating at work and influence workers' decisions on healthy food consumption.

Prior research work has suggested that occupational stress and time availability at work influence workers' eating behaviors [20-22,29-31]. This research has focused mainly on how stress or stressful events are related to unhealthy eating behaviors or intake of low-nutrient food, but it remains unclear to what extent occupational stressors (e.g., workload) may contribute to SSB consumption as meal substitutes during work. It has been reported that unhealthy eating behaviors are prevalent among Asian hospital nurses [12-14]. Therefore, the aim of this paper was to examine (a) the associations between substituting meals with SSBs and obesity prevalence and $(b)$ the associations between workload and SSB consumption as substitutes at work. We also estimated the adjusted population attributable risk (aPAR) of workload to suggest the possible implications of this study. We hypothesized that higher workloads would be associated with an increased likelihood of SSB meal replacement when working.

\section{Material and Methods}

\subsection{Study Design and Sample}

A national cross-sectional study of Taiwanese hospital nurses was undertaken. The inclusion criteria included: (a) nurses working fulltime (i.e., at least 30 hours per week on average) in accredited Taiwanese hospitals [32] and (b) aged 20-65 years old. The exclusion criteria included: (a) administrative work position (e.g., Director) and (b) working less than six months as a nurse in the hospital.

We employed a random sampling method with partial replacement to sample participants across Taiwan. Briefly, random sampling was undertaken by listing all accredited hospitals in Taiwan [32] and then applying a systematic cluster sampling method to select approximately $2 \%-8 \%$ of the hospitals from each geographical region (i.e., north, middle, south, east) of Taiwan. Excel's RANDBETWEEN function was employed to generate a random number between 1 and 10 for each region, and every tenth hospital was selected.

The number of recruited nurses in each hospital varied depending on the level (i.e., medical centers, regional hospitals, district hospitals, or psychiatric hospitals) and total nurse workforce. If a sampled hospital refused to participate or employed less than ten nurses, we alternatively invited the same-level accredited hospitals in the same region as substitutes. As a result, 10 medical centers, 16 regional hospitals, and 10 district hospitals were sampled. In Taiwan, most medical centers are large hospital complexes with over a thousand beds [33]. 


\subsection{Data Collection}

This study protocol was approved by the Institutional Review Boards (IRBs) at the National Taiwan University Hospital (No. 201612249RINC). Participant recruitment was conducted using the following sequence: after obtaining permission from collaborating hospital, we mailed the questionnaire to each hospital with instructions for questionnaire distribution and collection including an expected timeline for collecting questionnaires from participants and returning questionnaires to the research team. Participants who returned the questionnaire received a gift with an equivalent value of NTD 100 (USD \$3.2) for questionnaire completion. If questionnaires were not returned after three weeks, we contacted the hospital once for follow-up. As a result of this process, between September 2017 and December 2017, a total of 1500 questionnaires were distributed, and 1292 questionnaires were returned (Figure S1). The overall response rate was $86.1 \%$.

We excluded questionnaires from nurses working in non-acute care departments (e.g., outpatient departments, hemodialysis rooms, or nursing homes) $(n=254)$, part-time nurses $(n=26)$, and incomplete questionnaires (i.e., any missing values) $(n=158)$.

\subsection{Measurement Tools}

We employed a structured questionnaire covering the following information: participants' characteristics (e.g., demographics), body mass index (BMI) derived from self-reported body heights $(\mathrm{cm})$ and weights $(\mathrm{kg})$, workload, work characteristics (e.g., hospital work units), and dietary consumption (e.g., SSBs, food).

\subsubsection{Workload}

Two items in the unmet basic physiological needs subscale (i.e., not having an intact 30 minute mealtime, having no time to fulfill personal needs such as drinking water or going to the bathroom) and one item in the work demand subscale (i.e., not having enough time to meet patients' demands) in the Nurse Occupational Stressor Scale (NOSS) [34] were employed to assess participants' workload. The NOSS has been tested among Taiwanese hospital nurses and shown to have good reliability (i.e., test-retest reliability: 0.92 for the NOSS scale; Cronbach's $\alpha$ : 0.69 for unmet basic physiological needs subscale). Each NOSS item was assessed on a 5 point Likert scale (i.e., never, rare, sometimes, often, always). In this study, a response indicating "always" or "often" was considered as a high workload level.

\subsubsection{SSB Consumption at Work}

A 10 item list of food/beverages (i.e., "desserts, snacks, instant noodles, fast food, fried food, handmade drinks, sugar-sweetened beverages, microwaved products, other") was employed to assess participants' food/beverage consumption at work. Each participant was asked the following questions: (a) "Do you consume any of the following items while working (please check all that apply)?"; (b) if any items were checked, they were further asked whether they substituted the aforementioned items for their meals during work time. We mainly focused on participants' different types of SSB consumption, consisting of either "commercial SSB" (soft drinks, energy drinks) or "handmade drinks" (bubble tea, milk tea with tapioca) as a meal replacement during work time.

\subsubsection{Covariates}

Covariates included demographics (i.e., age, sex, educational attainment, marital status), other health-related personal characteristics (i.e., health history, habitual sleep duration on work days), and work characteristics (i.e., work tenure, weekly working hours, primary shift schedule in the past three months, hospital work units, and hospital levels). 


\subsection{Statistical Analysis}

The software JMP 9.0 (SAS Institute Inc., Cary, NC, 1989-2019) was employed for data analysis. Participants' characteristics were summarized using descriptive statistics. Associations between SSB consumption as a meal replacement when working and the likelihood of obesity, defined as BMI $>=27 \mathrm{~kg} / \mathrm{m}^{2}$, were analyzed using bivariate and age/sex-adjusted log binomial regression models.

To examine associations between workload and nurses' SSB consumption at work, we employed bivariate log binomial regression models to estimate crude associations. Based on the log likelihood ratio test (LRT), with the significance level at 0.05 , we identified significant covariates for respective pairs of predictors and outcome measures (e.g., workload and SSB consumption). We then adjusted the same-set of covariates (i.e., age, sex, health history, habitual sleep duration on work days, and hospital levels) in their respective models. Multivariate log binomial regression models were employed for hypothesis testing, and based on these results, the adjusted population attributable risk (aPAR) of each significant predictor was estimated.

\section{Results}

A total of 854 participants were included in the final analysis. As shown in Table 1, participants were at the mean age of 30.9 years old $(\mathrm{SD}=7.1)$, mostly female $(96.1 \%)$, with a bachelor's degree or above $(74.8 \%)$, non-obese (i.e., BMI $<27)(85.6 \%)$, and did not have any chronic diseases $(82.6 \%)$. Participants had worked as a nurse for an average of 8.3 years $(\mathrm{SD}=6.8)$. Almost two-thirds of all participants (64.2\%) consistently experienced high workloads.

Table 1. Participants' characteristics $(N=854)$.

\begin{tabular}{|c|c|c|}
\hline Variables & Mean (SD) & $n(\%)$ \\
\hline \multicolumn{3}{|l|}{ Demographics } \\
\hline Age (in years) & $30.9(7.1)$ & \\
\hline Female & & $821(96.1)$ \\
\hline \multicolumn{3}{|l|}{ Education attainment } \\
\hline Vocational school/associate degree & & $215(25.2)$ \\
\hline Bachelor's degree or above & & $639(74.8)$ \\
\hline \multicolumn{3}{|l|}{ Marital status } \\
\hline Married/cohabitation & & $286(33.5)$ \\
\hline Single/divorced/widowed/separated & & $568(66.5)$ \\
\hline \multicolumn{3}{|l|}{ Health-related personal characteristics } \\
\hline \multirow{2}{*}{\multicolumn{3}{|c|}{ Obesity ${ }^{-1}$}} \\
\hline & & \\
\hline No & & $731(85.6)$ \\
\hline Yes & & $123(14.4)$ \\
\hline \multicolumn{3}{|l|}{ Health history } \\
\hline None & & 705 (82.6) \\
\hline Having at least one chronic disease ${ }^{2}$ & & 149 (17.4) \\
\hline Sleep duration on work days (in hours) & $6.9(1.3)$ & \\
\hline \multicolumn{3}{|l|}{ Work characteristics } \\
\hline Work tenure as a RN (in years) & $8.3(6.8)$ & \\
\hline Weekly working hours & $44.2(7.1)$ & \\
\hline$<48$ & & $612(71.7)$ \\
\hline$>=48$ & & $242(28.3)$ \\
\hline \multicolumn{3}{|l|}{ Primary shift schedule in the past 3 months } \\
\hline Day shift & & $285(33.4)$ \\
\hline
\end{tabular}


Table 1. Cont.

\begin{tabular}{|c|c|c|}
\hline Variables & Mean (SD) & $n(\%)$ \\
\hline Evening shift & & $201(23.5)$ \\
\hline Night shift & & $147(17.2)$ \\
\hline Rotating shift & & $221(25.9)$ \\
\hline \multicolumn{3}{|l|}{ Hospital work units } \\
\hline Acute care ward ${ }^{3}$ & & $444(52.0)$ \\
\hline Special care units 4 & & $410(48.0)$ \\
\hline \multicolumn{3}{|l|}{ Hospital levels } \\
\hline Medical center & & $185(21.7)$ \\
\hline \multicolumn{3}{|l|}{ Workload conditions } \\
\hline Not having 30 minute mealtime & & $438(51.3)$ \\
\hline No time to fulfill personal needs & & $279(32.7)$ \\
\hline Not having enough time to meet patients' demands & & $108(12.6)$ \\
\hline Any of the above workload conditions & & $548(64.2)$ \\
\hline
\end{tabular}

Abbreviation: SD—standard deviation; BMI—body mass index; RN—registered nurse. ${ }^{1}$ Obesity was defined as BMI $>=27 \mathrm{~kg} / \mathrm{m}^{2}$ based on the recommendations from the Health Promotion Administration, Ministry of Health and Welfare. The overall BMI for general population ages 19-64 is between 23.0 and $24.0 \mathrm{~kg} / \mathrm{m}^{2}$ among females. The prevalence rate of obesity among the female population ages $19-30$ and $31-44$ are $14.6 \%$ and $19.0 \%$, respectively. In contrast, the overall BMI for the male general population age 19-64 is between 24.5 and $25.0 \mathrm{~kg} / \mathrm{m}^{2}$. The respective prevalence rates of obesity among male population ages $19-30$ and $31-44$ are $17.0 \%$ and $32.3 \%$, respectively; ${ }^{2}$ chronic diseases included hypertension, diabetes, cardiovascular disease, hyperlipidemia, hyperthyroidism, hypothyroidism, cancer, gastrointestinal diseases, and polycystic ovary syndrome (PCOS); ${ }^{3}$ acute care wards included surgical, medical, pediatric, gynecological, orthopedic, and psychiatric wards; ${ }^{4}$ special care units referred to emergency room, operating room, and intensive care units.

Table 2 shows participants' SSB consumption by workload. Almost half of all participants consumed commercial SSBs as a meal replacement when they encountered high workloads $(40.9 \%-47.2 \%)$. They also replaced meals with handmade drinks during high workload shifts $(53.9 \%-58.3 \%)$.

Table 2. Sugar sweetened beverage consumption as meal replacements at work by workload conditions $(N=854)$.

\begin{tabular}{|c|c|c|c|c|c|}
\hline Variables & Overall & $\begin{array}{l}\text { Not Having a } \\
30 \text { Minute } \\
\text { Mealtime } \\
(n=438)\end{array}$ & $\begin{array}{l}\text { No Time to Fulfill } \\
\text { Personal Needs } \\
\quad(n=279)\end{array}$ & $\begin{array}{c}\text { Not Having Enough } \\
\text { Time to Meet Patients' } \\
\text { Demands } \\
(n=108)\end{array}$ & $\begin{array}{c}\text { Any High } \\
\text { Workload } \\
\text { Condition }{ }^{1} \\
(n=548)\end{array}$ \\
\hline & $n(\%)$ & $n(\%)$ & $n(\%)$ & $n(\%)$ & $n(\%)$ \\
\hline Commercial SSBs & $293(34.3)$ & $183(41.8)$ & $114(40.9)$ & $51(47.2)$ & $218(39.8)$ \\
\hline Handmade drinks & $420(49.2)$ & $236(53.9)$ & $159(57.0)$ & $63(58.3)$ & $292(53.3)$ \\
\hline Total SSB intake 2 & $492(57.6)$ & $288(65.8)$ & $183(65.6)$ & $76(70.4)$ & 349 (63.7) \\
\hline
\end{tabular}

SSB: sugar-sweetened beverage. ${ }^{1}$ refers to any of the high workload conditions listed; ${ }^{2}$ total SSB intake refers to either commercial SSB or handmade drink consumption.

Participants who substituted meals with commercial SSBs had a 40\% increase in the likelihood of obesity (aPRR $=1.4,95 \% \mathrm{CI}(1.1,1.7)$ ), adjusting for age and sex (Table 3). Further, there was a $1.2(95 \% \mathrm{CI}(1.0,1.5))$ increased risk of obesity for participants who consumed handmade drinks as meal substitutes. 
Table 3. Associations between SSB consumption and nurses' obesity $(N=854)$.

\begin{tabular}{ccc}
\hline \multirow{2}{*}{ Variables } & \multicolumn{2}{c}{ Obesity $\mathbf{( B M I}>=\mathbf{2 7})$} \\
\cline { 2 - 3 } & PRR (95\% CI) & aPRR $^{\mathbf{1}} \mathbf{( 9 5 \%} \mathbf{~ C I )}$ \\
\hline Commercial SSBs & $1.3(1.1,1.6)^{* *}$ & $1.4(1.1,1.7)^{* *}$ \\
Handmade drinks & $1.1(0.9,1.4)$ & $1.2(1.0,1.5)$ \\
Total SSB intake $^{2}$ & $1.1(0.9,1.3)$ & $1.2(1.0,1.4)$ \\
\hline
\end{tabular}

SSB: sugar-sweetened beverage, PRR: prevalence rate ratio, CI: confidence interval, aPRR: adjusted prevalence rate ratio. ${ }^{1}$ the estimates were adjusted for age and sex; ${ }^{2}$ total SSB intake refers to either commercial SSB or handmade drink consumption; ** $p<0.01$.

\section{Workload and SSB Consumption}

Adjusting for covariates, there was a statistically increased risk of replacing meals with SSBs when workload was high (Table 4). Participants exposed to any of the high workload conditions had a higher risk of consuming SSBs as meal replacements ( $\mathrm{aPRR}=1.4,95 \% \mathrm{CI}(1.2,1.6)$ ). The estimated aPAR revealed that approximately $20 \%$ of nurses substituting SSBs for meals during work could be prevented $(\mathrm{PAR}=19.0,95 \% \mathrm{CI}(10.8,26.1))$ if the high workload condition was removed.

Table 4. Associations between workload and SSB consumption at work $(N=854)$.

\begin{tabular}{|c|c|c|c|c|}
\hline & $\%$ Exposed (E|D) ${ }^{1}$ & $\operatorname{PRR}(95 \% \mathrm{CI})^{2}$ & $\operatorname{aPRR}(95 \% \mathrm{CI})^{3}$ & aPAR $(95 \% \text { CI })^{4}$ \\
\hline Workload conditions & & & & \\
\hline $\begin{array}{c}\text { Not having a } 30 \text { minute } \\
\text { mealtime }\end{array}$ & 58.5 & $1.4(1.2,1.6)^{* * *}$ & $1.4(1.2,1.6)^{* * *}$ & \\
\hline No time to fulfill personal needs & 37.2 & $1.3(1.1,1.5)^{* * *}$ & $1.2(1.0,1.4)^{*}$ & \\
\hline $\begin{array}{l}\text { Not having enough time to meet } \\
\text { patients' demands }\end{array}$ & 15.5 & $1.4(1.1,1.7)^{* *}$ & $1.3(1.1,1.7)^{*}$ & \\
\hline $\begin{array}{c}\text { Any of the above workload } \\
\text { conditions }\end{array}$ & 70.9 & $1.4(1.2,1.6)^{* * *}$ & $1.4(1.2,1.6)^{* * *}$ & $19.0(10.8,26.1)$ \\
\hline
\end{tabular}

PRR: prevalence rate ratio, aPRR: adjusted prevalence rate ratio, aPAR: adjusted population attributable risks, SSB: sugar-sweetened beverage. ${ }^{1} \mathrm{E} \mid \mathrm{D}$ : among those who consumed SSBs, the proportion of participants who were exposed to the independent variables; ${ }^{2}$ respective aPRRs were estimated using the log binomial regression models; ${ }^{3}$ each model adjusted for age, sex, health history, habitual sleep duration on workdays, and hospital level; ${ }^{4}$ respective aPARs were calculated based on the following formula: $\mathrm{P}(\mathrm{E} \mid \mathrm{D}) \times((\mathrm{aPRR}-1) / \mathrm{aPRR}){ }^{*} p<0.05,{ }^{* *} p<0.01$, *** $p<0.001$.

\section{Discussion}

To the best of our knowledge, this is the first study to link nurse's SSB consumption with workload and obesity. The main finding was that nurses who used SSBs as meal replacements during work were more likely to be obese. Further, workload was positively associated with an increased risk of replacing meals with SSBs. Therefore, workers with high workloads were not eating meals but used SSBs as meal substitutes which may contribute to weight gain and obesity despite the increased work demands. With many Asian countries increasingly including Western-type foods and beverages into their diets, the need for workplace and dietary education is warranted. It is suggested that if healthcare workplace employers could reduce high workload conditions, up to one in five unhealthy eating behaviors during work time could be prevented.

There is considerable evidence showing the positive associations between obesity $[6,8,10,35]$ and weight gain risk $[36,37]$ and SSB consumption. The exact causes of these associations are not clear, but research suggests that SSB consumption is not counterbalanced by a reduction in food intake [38], and consumption of SSBs may increase appetite, leading to excess daily energy consumption [39]. While the participants in this study used SSBs as meal replacements at work, they may also have consumed meals with increased energy outside of work; however, this was not explored in this study. Several prospective cohort studies have revealed the efficacy of reducing the intake of SSBs on the risk of long-term weight gain [9] and the prevalence of overweight or obesity [5]. This may also reduce the risk of chronic diseases (e.g., type 2 diabetes, cardiovascular diseases) [3-7]. 
Occupational stress and reduced time availability at work have been associated with workers' unhealthy eating behaviors [11,40]. A study of health care workers showed that not having enough time for a meal break was the most common barrier for workers' healthy eating [29]. Among overweight/obese workers, Leung and colleagues [41] came to the same conclusion that workers tended to consume more low-nutrient foods in reaction to stress and time constraints in the workplace. We found that limited time availability due to the fact of a high workload increased the likelihood of SSB consumption as meal replacements and workers are consuming energy-rich drinks to cope with a lack of available meal-time which is changing eating behavior and is potentially obesogenic. It is not clear from our study which occupational factors contribute to the limited time availability for meals. This could be attributed to inadequate staffing or acuity and complexity of patients' conditions. It is likely that there were multiple factors causing this phenomenon. There needs to be longitudinal research to determine the effects of these modified workplace behaviors on workers' diet and obesity.

\section{Strengths and Limitations}

A large representative sample of Taiwanese hospital nurses was recruited to examine associations between workload and SSB consumption at work. The main strength of this study is that the random sampling method increased the generalizability of this study. However, it should be noted that we excluded responses from hospital registered nurses working in non-acute care departments (e.g., outpatient departments) and part-time nurses. Therefore, the result of this study may only be generalized to hospital nurses working in acute care departments (e.g., surgical wards) and full-time nurses. In addition, several limitations should not be ignored in this study. First, using the cross-sectional study design, the causal inferences of associations between high workload and SSB consumption as meal replacements at work still could not be determined. However, using the log binomial regression model helps to reduce the possibility of inflated point estimates from logistic regression models. Second, the results were based on self-reported measures, and it is possible that recall bias may threaten the internal validity of the findings. Using a food/beverage checklist for dietary assessments may have contributed to measurement error which may have resulted in misclassification and underestimation of the association.

\section{Conclusions}

This is the first study to show that high workload is strongly associated with an increased likelihood of substituting SSBs for meals during work, and this was more pronounced in obese workers. The potential effects of these behaviors may lead to increased obesity and obesity-related diseases. This is particularly relevant to Asian countries, where existing dietary patterns are increasingly being influenced by Western foods, and consumption of high energy foods and drinks is increasing. Asian nurses may be particularly vulnerable due to the high workloads, and this study clearly demonstrates that they are substituting meals with SSB consumption. Furthermore, it was significantly influencing those nurses who were obese. It is recommended that workplace conditions guarantee an adequate mealtime to reduce the probability of SSB meal replacement.

Supplementary Materials: The following are available online at http://www.mdpi.com/1660-4601/16/24/4984/s1, Figure S1: Process of data collection.

Author Contributions: T.-T.L. developed the concept of this manuscript, analyzed and presented data, reviewed the literature, and wrote the first draft of this manuscript. Y.L.G. developed the study protocol, the concept of this manuscript, analyzed data, wrote and revised this manuscript. C.G. and E.C. contributed to manuscript writing and revision. Y.-C.C. was responsible for data collection and processed the raw dataset. C.-M.O. contributed to the literature review and revised this manuscript. J.S.-C.S. developed the study protocol, concept, and revised this manuscript to its final version. All authors read and approved the final manuscript.

Funding: This study was funded by the National Taiwan University-University of Sydney Partnership Collaboration Awards.

Acknowledgments: We sincerely thank all participants for their contributions to this study. 
Conflicts of Interest: The authors have declared that they have no conflict of interest.

\section{References}

1. Klingberg, S.; Mehlig, K.; Johansson, I.; Lindahl, B.; Winkvist, A.; Lissner, L. Occupational stress is associated with major long-term weight gain in a swedish population-based cohort. Int. Arch. Occup. Environ. Health 2019, 92, 569-576. [CrossRef] [PubMed]

2. Yeh, T.L.; Chen, H.H.; Chiu, H.H.; Chiu, Y.H.; Hwang, L.C.; Wu, S.L. Morbidity associated with overweight and obesity in health personnel: A 10-year retrospective of hospital-based cohort study in taiwan. Diabetes Metab. Syndr. Obes. 2019, 12, 267-274. [CrossRef] [PubMed]

3. Hruby, A.; Manson, J.E.; Qi, L.; Malik, V.S.; Rimm, E.B.; Sun, Q.; Willett, W.C.; Hu, F.B. Determinants and consequences of obesity. Am. J. Public Health 2016, 106, 1656-1662. [CrossRef] [PubMed]

4. Hu, F.B. Resolved: There is sufficient scientific evidence that decreasing sugar-sweetened beverage consumption will reduce the prevalence of obesity and obesity-related diseases. Obes. Rev. 2013, 14, 606-619. [CrossRef] [PubMed]

5. Ma, Y.; He, F.J.; Yin, Y.; Hashem, K.M.; MacGregor, G.A. Gradual reduction of sugar in soft drinks without substitution as a strategy to reduce overweight, obesity, and type 2 diabetes: A modelling study. Lancet Diabetes Endocrinol. 2016, 4, 105-114. [CrossRef]

6. Malik, V.S.; Popkin, B.M.; Bray, G.A.; Despres, J.P.; Hu, F.B. Sugar-sweetened beverages, obesity, type 2 diabetes mellitus, and cardiovascular disease risk. Circulation 2010, 121, 1356-1364. [CrossRef] [PubMed]

7. Wilson, P.W.; D'Agostino, R.B.; Sullivan, L.; Parise, H.; Kannel, W.B. Overweight and obesity as determinants of cardiovascular risk: The framingham experience. Arch. Intern. Med. 2002, 162, 1867-1872. [CrossRef]

8. Malik, V.S.; Hu, F.B. Sweeteners and risk of obesity and type 2 diabetes: The role of sugar-sweetened beverages. Curr. Diabetes Rep. 2012, 12, 195-203. [CrossRef]

9. Pan, A.; Malik, V.S.; Hao, T.; Willett, W.C.; Mozaffarian, D.; Hu, F.B. Changes in water and beverage intake and long-term weight changes: Results from three prospective cohort studies. Int. J. Obes. 2013, 37, 1378-1385. [CrossRef]

10. Shin, S.; Kim, S.A.; Ha, J.; Lim, K. Sugar-sweetened beverage consumption in relation to obesity and metabolic syndrome among korean adults: A cross-sectional study from the 2012-2016 korean national health and nutrition examination survey (knhanes). Nutrients 2018, 10, 1467. [CrossRef]

11. Gifkins, J.; Johnston, A.; Loudoun, R. The impact of shift work on eating patterns and self-care strategies utilised by experienced and inexperienced nurses. Chronobiol. Int. 2018, 35, 811-820. [CrossRef] [PubMed]

12. Chang, S.J.; Liao, W.C. Prevalence of and risk factors associated with metabolic syndrome among nurses. Taiwan J. Public Health 2015, 34, 268-283.

13. Tsai, S.M.; Wong, R.H.; Hwang, S.L.; Yang, H.C.; Lin, Y.C.; Liao, W.C. A study relating shift work to the parameters of metabolic syndrome among nurses in a medical center. Taiwan J. Public Health 2014, 33, 119-130.

14. Han, K.; Choi-Kwon, S.; Kim, K.S. Poor dietary behaviors among hospital nurses in seoul, south korea. Appl. Nurs. Res. 2016, 30, 38-44. [CrossRef] [PubMed]

15. Brunner, E.J.; Chandola, T.; Marmot, M.G. Prospective effect of job strain on general and central obesity in the whitehall ii study. Am. J. Epidemiol. 2007, 165, 828-837. [CrossRef] [PubMed]

16. Lallukka, T.; Lahelma, E.; Rahkonen, O.; Roos, E.; Laaksonen, E.; Martikainen, P.; Head, J.; Brunner, E.; Mosdol, A.; Marmot, M.; et al. Associations of job strain and working overtime with adverse health behaviors and obesity: Evidence from the whitehall ii study, helsinki health study, and the japanese civil servants study. Soc. Sci. Med. 2008, 66, 1681-1698. [CrossRef]

17. Kivimaki, M.; Head, J.; Ferrie, J.E.; Shipley, M.J.; Brunner, E.; Vahtera, J.; Marmot, M.G. Work stress, weight gain and weight loss: Evidence for bidirectional effects of job strain on body mass index in the whitehall ii study. Int. J. Obes. 2006, 30, 982-987. [CrossRef]

18. Nyberg, S.T.; Heikkila, K.; Fransson, E.I.; Alfredsson, L.; De Bacquer, D.; Bjorner, J.B.; Bonenfant, S.; Borritz, M.; Burr, H.; Casini, A.; et al. Job strain in relation to body mass index: Pooled analysis of 160000 adults from 13 cohort studies. J. Intern. Med. 2012, 272, 65-73. [CrossRef]

19. Lazarus, R.S.; Folkman, S. Stress, Appraisal, and Coping; Springer: New York, NY, USA, 1984.

20. Groesz, L.M.; McCoy, S.; Carl, J.; Saslow, L.; Stewart, J.; Adler, N.; Laraia, B.; Epel, E. What is eating you? Stress and the drive to eat. Appetite 2012, 58, 717-721. [CrossRef] 
21. Jarvela-Reijonen, E.; Karhunen, L.; Sairanen, E.; Rantala, S.; Laitinen, J.; Puttonen, S.; Peuhkuri, K.; Hallikainen, M.; Juvonen, K.; Myllymaki, T.; et al. High perceived stress is associated with unfavorable eating behavior in overweight and obese finns of working age. Appetite 2016, 103, 249-258. [CrossRef]

22. King, K.A.; Vidourek, R.; Schwiebert, M. Disordered eating and job stress among nurses. J. Nurs. Manag. 2009, 17, 861-869. [CrossRef] [PubMed]

23. Errisuriz, V.L.; Pasch, K.E.; Perry, C.L. Perceived stress and dietary choices: The moderating role of stress management. Eat. Behav. 2016, 22, 211-216. [CrossRef] [PubMed]

24. Wardle, J.; Steptoe, A.; Oliver, G.; Lipsey, Z. Stress, dietary restraint and food intake. J. Psychosom. Res. 2000, 48, 195-202. [CrossRef]

25. Ng, D.M.; Jeffery, R.W. Relationships between perceived stress and health behaviors in a sample of working adults. Health Psychol. 2003, 22, 638-642. [CrossRef] [PubMed]

26. Tryon, M.S.; Carter, C.S.; Decant, R.; Laugero, K.D. Chronic stress exposure may affect the brain's response to high calorie food cues and predispose to obesogenic eating habits. Physiol. Behav. 2013, 120, $233-242$. [CrossRef] [PubMed]

27. Ashton, L.M.; Hutchesson, M.J.; Rollo, M.E.; Morgan, P.J.; Collins, C.E. Motivators and barriers to engaging in healthy eating and physical activity. Am. J. Men's Health 2017, 11, 330-343. [CrossRef] [PubMed]

28. Monsivais, P.; Aggarwal, A.; Drewnowski, A. Time spent on home food preparation and indicators of healthy eating. Am. J. Prev. Med. 2014, 47, 796-802. [CrossRef]

29. Leslie, J.H.; Braun, K.L.; Novotny, R.; Mokuau, N. Factors affecting healthy eating and physical activity behaviors among multiethnic blue- and white-collar workers: A case study of one healthcare institution. Hawai'i J. Med. Public Health 2013, 72, 300-306.

30. Waterhouse, J.; Buckley, P.; Edwards, B.; Reilly, T. Measurement of, and some reasons for, differences in eating habits between night and day workers. Chronobiol. Int. 2003, 20, 1075-1092. [CrossRef]

31. Persson, M.; Martensson, J. Situations influencing habits in diet and exercise among nurses working night shift. J. Nurs. Manag. 2006, 14, 414-423. [CrossRef]

32. Ministry of Health and Welfare. List of Accredited Hospitals 2013-2016. Available online: https://www. mohw.gov.tw/dl-23917-a2e699bc-f0bd-4d32-adff-6cde28f57e1a.html (accessed on 1 May 2017).

33. Ministry of Health and Welfare. Statistics of Medical Care Institution's Status E Hospital's Utilization 2017; Ministry of Health and Welfare: Taipei, Taiwan, 2018.

34. Hu, P.Y.; Shiao, S.C. A study on practice environment and physical and mental health of nurses in taiwan; Institute of Labor, Occupational Safety And Health, Ministry of Labor: New Taipei City, Taiwan, 2014.

35. Hu, F.B.; Malik, V.S. Sugar-sweetened beverages and risk of obesity and type 2 diabetes: Epidemiologic evidence. Physiol. Behav. 2010, 100, 47-54. [CrossRef] [PubMed]

36. Malik, V.S.; Pan, A.; Willett, W.C.; Hu, F.B. Sugar-sweetened beverages and weight gain in children and adults: A systematic review and meta-analysis. Am. J. Clin. Nutr. 2013, 98, 1084-1102. [CrossRef] [PubMed]

37. Mozaffarian, D.; Hao, T.; Rimm, E.B.; Willett, W.C.; Hu, F.B. Changes in diet and lifestyle and long-term weight gain in women and men. N. Engl. J. Med. 2011, 364, 2392-2404. [CrossRef] [PubMed]

38. Vartanian, L.R.; Schwartz, M.B.; Brownell, K.D. Effects of soft drink consumption on nutrition and health: A systematic review and meta-analysis. Am. J. Public Health 2007, 97, 667-675. [CrossRef] [PubMed]

39. St-Onge, M.P.; Rubiano, F.; DeNino, W.F.; Jones, A., Jr.; Greenfield, D.; Ferguson, P.W.; Akrabawi, S.; Heymsfield, S.B. Added thermogenic and satiety effects of a mixed nutrient vs a sugar-only beverage. Int. J. Obes. 2004, 28, 248-253. [CrossRef]

40. Lowden, A.; Moreno, C.; Holmback, U.; Lennernas, M.; Tucker, P. Eating and shift work—Effects on habits, metabolism and performance. Scand. J. Work Environ. Health 2010, 36, 150-162. [CrossRef]

41. Leung, S.L.; Barber, J.A.; Burger, A.; Barnes, R.D. Factors associated with healthy and unhealthy workplace eating behaviours in individuals with overweight/obesity with and without binge eating disorder. Obes. Sci. Pract. 2018, 4, 109-118. [CrossRef]

(C) 2019 by the authors. Licensee MDPI, Basel, Switzerland. This article is an open access article distributed under the terms and conditions of the Creative Commons Attribution (CC BY) license (http://creativecommons.org/licenses/by/4.0/). 